\title{
Linking sewage pollution and water quality to spatial patterns of Porites lobata growth anomalies in Puakō, Hawai'i
}

Reyn M. Yoshioka

Department of Ecology and Evolutionary Biology, Cornell University, Ithaca, NY 14853 USA

Catherine J.S. Kim*

Department of Ecology and Evolutionary Biology, Cornell University, Ithaca, NY 14853 USA

Allison M. Tracy

Department of Ecology and Evolutionary Biology, Cornell University, Ithaca, NY 14853 USA

Rebecca Most

The Nature Conservancy, 923 Nuuanu Ave., Honolulu, HI, 96817

C. Drew Harvell

Department of Ecology and Evolutionary Biology, Cornell University, Ithaca, NY 14853 USA

Corresponding Author:

Reyn M. Yoshioka

323 Corson Hall, Department of Ecology and Evolutionary Biology, Cornell University, Ithaca, NY 14853 USA

rmy27@cornell.edu

808-217-2907

* Present Affiliation:

School of Biological Sciences, University of Queensland, St. Lucia, QLD 4072 Australia 


\begin{abstract}
:
Sewage pollution threatens the health of coastal populations and ecosystems, including coral reefs. We investigated spatial patterns of sewage pollution in Puakō, Hawai' $i$ using enterococci concentrations and $\delta^{15} \mathrm{~N}$ Ulva fasciata macroalgal bioassays to assess relationships with the coral disease Porites lobata growth anomalies (PGAs). PGA severity and enterococci concentrations were high, spatially variable, and positively related. Bioassay algal $\delta^{15} \mathrm{~N}$ showed low sewage pollution at the reef edge while high values of resident algae indicated sewage pollution nearshore. Neither $\delta^{15} \mathrm{~N}$ metric predicted PGA measures, though bioassay $\delta^{15} \mathrm{~N}$ was negatively related to coral cover. Furthermore, PGA prevalence was much higher than previously recorded in Hawai' $i$ and the greater Indo-Pacific, highlighting Puakō as an area of concern. Although further work is needed to resolve the relationship between sewage pollution and coral cover and disease, these results implicate sewage pollution as a contributor to diminished reef health.
\end{abstract}

\title{
Keywords:
}

coral disease; Porites growth anomaly; sewage pollution; $\delta^{15} \mathrm{~N}$; Hawai ‘i; enterococci

\section{Introduction}

Coral disease is a significant factor in declining coral health throughout the world (RuizMoreno et al. 2012), and is often exacerbated by global and local stressors, such as increasing water temperature and sedimentation (rev. in Harvell et al. 2007). One widespread anthropogenic stressor impacting coral reef ecosystems is sewage pollution. Sewage pollution is not a single, simple stressor; rather, it is complex and can introduce diverse pollutants, including nutrients (especially nitrogen and phosphorous), microbial pathogens, and chemical contaminants that themselves can impact coral reefs (Wear \& Vega Thurber 2015).

One component of sewage, nutrient pollution, can be an important facilitator of coral disease. Couch et al. (2008) suggest that nutrient enrichment may favor growth of coral microbial associates, which indirectly modifies host coral immunity by requiring an elevated immune response. Increases in nutrient loading can increase the severity and prevalence of coral disease, possibly by favoring pathogen growth or inhibiting resistance (Bruno et al. 2003; Voss and Richardson 2006; Harvell et al. 2007; Vega Thurber et al. 2014). It is important to note that there are several sources of nutrient influx to coral reefs, which include runoff (Fabricius 2005), fish farm effluents (Garcia-Sanz et al. 2011), and other natural terrestrial and atmospheric contributions (Szmant 2002). Sewage pollution can also introduce pathogens, as is the case with the human gut microbe, Serratia marcescens. This microbe has been considered responsible for white pox disease in the Caribbean and the resulting decimation of the now endangered Acropora palmata corals (Sutherland et al. 2010), though this relationship is disputed (Lesser et al. 2014). A third possible contribution of sewage pollution to coral disease is chemical contaminants such as endocrine disruptors, heavy metals, and other toxins (rev. in Wear \& Vega Thurber 2015).

Other human gut bacteria can also enter the marine environment through sewage pollution. While not necessarily pathogenic, these bacteria are of interest as indicators of untreated sewage entering coral reef ecosystems. The gram-positive Enterococcus spp. bacteria are used by the US Environmental Protection Agency (EPA) as a water quality metric and to assess the degree of sewage pollution. Naturally found as facultative anaerobes in human and 
animal guts, enterococci are relatively persistent bacteria and are able to tolerate both fresh and saline water.

Compared to typical seawater, sewage-polluted water is enriched in ${ }^{15} \mathrm{~N}$ relative to ${ }^{14} \mathrm{~N}$, and therefore, has a highly positive $\delta^{15} \mathrm{~N}$ value $(>10 \%)$, which distinguishes it from other nitrogen sources such as fertilizers or $\mathrm{N}_{2}$-fixing plants $(\sim 0 \%$ ) (Heaton 1986, Derse et al. 2007; Risk et al. 2009; Dailer et al. 2010). The enrichment of ${ }^{15} \mathrm{~N}$ in the environment is reflected in macroalgae and other biological tissues, allowing bioassays to be used to detect enrichment of ${ }^{15} \mathrm{~N}$ and thus indicate sewage pollution (Risk et al. 2009). There is a large range of $\delta^{15} \mathrm{~N}$ values that could indicate sewage pollution in macroalgae ( 3 to $>10 \%$ ), but levels typically decrease with increasing distance from the pollution source (Heaton 1986, Costanzo et al. 2001, Risk et al. 2009). In Dailer et al. (2011), the alga Ulva fasciata was grown in waters off West Hawai' $i$ to produce a sample that integrated levels of nitrogen over a 1-week period. Dailer et al. (2010) also used $\delta^{15} \mathrm{~N}$ analysis on resident algae to map sewage pollution in Maui, Hawai' $\mathrm{i}$. Similar studies have been performed in both temperate and tropical environments; for example, bioassays of the oyster Crassostrea virginica and macroalga Gracilaria sp. were used to detect sewage and animal waste pollution in coastal Maryland, USA (Fertig et al., 2009) and Moynihan et al. (2012) used a combination of enterococci concentration measurements and $\delta^{15} \mathrm{~N}$ analysis of seagrass, scleractinian corals, sponges, and macroalgae in Zanzibar, Tanzania.

In Puakō, Hawai'i, untreated sewage pollution can enter the coral reef ecosystem through the combination of old cesspool systems, highly porous volcanic bedrock, and close proximity to the shore via submarine groundwater discharge (SGD) (Street et al. 2008; Knee et al. 2010). This region of the leeward coast of Hawai' $i$ Island (West Hawai' $i$ ) has particularly well-developed reefs. However, as with many other coastal regions of Hawai' $i$, the Puakō region has experienced increased pressures from fishing, land-based pollution, recreational use, development, and likely climate change in recent decades. The consequences of these compounding impacts likely explain the dramatic decline of Puakō marine resources over the long term. Data compiled by The Nature Conservancy and the Hawai'i State Division of Aquatic Resources show a decrease in fish abundance over a 40-year span (Minton et al. 2012; Walsh 2013). Coral cover also declined dramatically in Puakō, dropping from $80 \%$ in the 1970 s to $32 \%$ in 2010 (Walsh 2013). Additionally, Couch et al. (2014) identified Puakō as one of four regions in West Hawai'i warranting special concern based on a 12\% reduction in coral cover between 2003 and 2011. While there are likely many contributing factors in this decline, it is important to consider the role of coastal pollution in facilitating coral disease and death. Community concern primarily focuses on sewage pollution; however, other pollutants and sources of nutrient inputs may include animal wastes from upland regions, and fertilizers and pesticides used in the area. The nitrogen-fixing tree Prosopis pallida is common in the area, but work in anchialine pools elsewhere suggests that its contribution to nitrogen inputs is minimal (Dudley et al. 2014).

Puakō reefs are dominated by Porites lobata corals, which are also the most vulnerable to disease (Friedlander et al. 2008; Aeby et al. 2011b; Couch et al. 2014). The most prevalent of these diseases is P. lobata Growth Anomalies (PGAs), which are identified as gross lesions of tumor-like tissue with lighter pigmentation, raised tissue, and enlarged or variable polyp (calyx) size (Fig. 1). The lighter pigmentation of PGAs is the result of lower densities of symbiotic dinoflagellates in PGA tissue. As a result, PGAs are likely unable to produce enough energy to sustain themselves and must rely on resources of healthy portions of the host to grow (Yasuda et al. 2012). As sinks for their colonies' resources and sites of decreased reproductive function, PGAs have the potential to decrease the reproductive ability and immunity of the whole colony 
(see Burns and Takabayashi 2011 for Montipora capitata growth anomaly impact). Although a viral microbial agent has been investigated (Vega Thurber and Correa 2011), the causative agent remains unknown and could even include somatic mutation (Irikawa et al. 2011).

Our study examines the relationships between PGAs, enterococci concentrations, and macroalgal $\delta^{15} \mathrm{~N}$ across 10 sites in Puakō to test the hypothesis that coral disease is higher in areas of sewage inputs. Because host properties can also influence disease in addition to environmental pollution, we also investigated the role of colony size in patterns of PGAs.

\section{Methods}

\subsection{The Puakō Region and Study Sites}

The Puakō region is located along the leeward, Kohala Coast of Hawai' $i$ Island, Hawai' $i$. The adjascent community is comprised one hundred sixty-three (163) houses. Cesspools and septic tanks provide the majority of wastewater treatment for the community, except for the condominium which uses an ejection well for primary treated sewage (Minton et al. 2012). The greater census-designated place has 772 residents and 2,326 housing units, which includes hotels and condominiums in the resort area nearby to the community of interest (US Census Bureau, 2010).

Ten study sites ranging from Waialea Bay to Paniau Bay were selected to capture variation in coral health and sewage pollution along $3 \mathrm{~km}$ of the Puakō coast (Fig. 2). Where possible, study sites were selected at shoreline access (SA) locations. SA sites (SA40, SA80, SA88, SA100, SA136, SA152), Condos, and Waialea were all located adjacent to residences. The road through the community hugs the shoreline such that most of the residences are immediately adjacent or across the road (inland) from the shoreline, forming a consistent strip two-houses deep along the SA sites. Paniau and Waialea are both public beaches, and PBR is a launching site for small boats, and Condos is near the condominiums complex in the community.

The region has a dry climate as does most of the leeward coast of the island. Freshwater entering the marine environment is primarily from upland areas and is delivered via underground aquifers through porous volcanic rock. Areas nearshore where the aquifers are exposed can create anchialine pools, which are surficially isolated from the ocean but are connected underground. The pools are mixohaline due to the combined influences of the freshwater aquifers and the ocean, and rise and fall with the tide. Anchialine pools sampled in this study were $102 \pm 12 \mathrm{~m}$ from the shore and in the same area as the more inland residences.

\subsection{Coral cover and disease surveys}

Three replicate $15-\mathrm{m}$ transects were laid haphazardly at each of the 10 site, approximately parallel to the reef edge in 2-3 m deep water to maintain consistency among sites. Ten $0.5 \times 0.5-$ $\mathrm{m}$ quadrats were placed along each side of the transect for a total of 20 quadrats per transect. To limit duplicate measures of large colonies spanning the transect line quadrats were placed alternately along $1.5-\mathrm{m}$ intervals on the line. Within each quadrat the number of PGAs on each colony, and the maximum diameter of each colony (here on referred to as "colony size"), and the percent coral cover were recorded. PGAs were identified based on gross appearance of raised skeleton with light pigmentation and large or irregular polyp size. PGA severity was recorded as the number of PGAs per colony and prevalence as the proportion of $P$. lobata colonies afflicted with PGAs. Live coral cover was estimated using 10 x $10-\mathrm{cm}$ grids within the quadrat. 


\subsection{Enterococci assays}

Shortly after low tide, five $100 \mathrm{~mL}$ water samples were collected at each site, with three along the open shoreline (25 June 2013) and two in the nearby tide pools, where visible exchange with the ocean was absent or restricted (3 July 2013). Although it would have been ideal to sample the water column directly over the coral survey transects, enterococci concentrations were expected to be too dilute for detection. Five anchialine pools (two samples per pool) were sampled in the Puakō area, as these were expected show a stronger influence of sewage if present, using the same methods as marine samples (28 June 2013). Water samples were kept on ice and processed within $6 \mathrm{~h}$ using methods similar to those described in the EPA Method 1600 and Baker et al. (2010), except substituting mEI agar with m-Enterococcus agar and incubating at $37^{\circ} \mathrm{C}$ for $48 \mathrm{hrs}$. Additionally, samples were collected in the following winter on 7 January 2014 and 13 January 2014, both after rainfall events (post-rainfall I and postrainfall II, resp.). Winter samples were collected at five of the 10 original sites (Waialea, Puakō Boat Ramp, Condos, SA80, and Paniau, $n=3-6$ per site per sampling time). Enterococci colony forming units (CFU) growing on $\mathrm{m}$-Enterococcus agar produce red colonies; the number of these colonies divided by the volume of water filtered provided the concentration of enterococci, here on presented as CFU/100 mL.

\section{4. $\delta^{15} N$ bioassay with $\mathrm{U}$. fasciata}

Ulva fasciata was collected from the shoreline at the Natural Energy Labs of Hawai' $i$ Authority due to very low abundance in Puakō. To minimize variation in initial algal $\delta^{15} \mathrm{~N}$ and starve the algae of nitrogen, samples were incubated onshore in naturally-lit aquaria in seawater collected $1 \mathrm{~km}$ offshore. It was assumed that the open ocean water would have sufficiently low nutrient concentrations to achieve nitrogen starvation; however, this was not verified. Over the seven-day incubation (based on methods in Dailer et al. 2010, 2011), half of the aquaria water was replaced with fresh seawater every two days.

After incubation, U. fasciata was divided into individual fronds, which were placed into cages of plastic fencing and zip ties. Labeled cages were deployed at reef level in five of the sites: Waialea, Condos, SA80, SA136, and Paniau ( $n=10$ per site). An additional 10 replicate fronds were reserved and processed to serve as initial measurements prior to deployment.

Resource limitations did not allow cages to be deployed at all sites; these were selected because they spanned the region and also captured areas of high human use and interest (Waialea, Condos, and Paniau). The U. fasciata were left to incubate for eight days, after which cages were collected, the fronds promptly rinsed in commercial bottled distilled freshwater, cleaned of debris, and dried. Dried samples were sent to Ithaca, NY, where they were ground in liquid nitrogen for $\delta^{15} \mathrm{~N}$ and $\% \mathrm{~N}$ analysis by the Cornell University Stable Isotope Laboratory (COIL), Ithaca, NY.

To determine whether the $\delta^{15} \mathrm{~N}$ of incubated algae would reflect the $\delta^{15} \mathrm{~N}$ of resident algae, resident $U$. fasciata were also collected from the shoreline ( $0-\mathrm{m}$ depth) adjacent to the Condos and SA80 study sites ( $\mathrm{n}=5$ per site), which were processed for stable isotope analysis similarly to incubated samples at COIL.

\subsection{Data analysis}

All data were analyzed in R version 3.0.1. Analysis of variance (ANOVA) with Tukey's post hoc HSD was used to determine differences in enterococci concentrations among sites. A binomial-family generalized linear mixed model (GLMM, in lme4, Bates et al. 2015) followed 
with a general linear hypothesis test (glht, in multcomp, Torsten et al. 2008) was used to examine the site-level differences of PGA prevalence with transect treated as a random effect. PGA severity was investigated similarly using a poisson-family GLMM and glht. Goodness-offit testing against the null model was done with likelihood ratio tests (LRT).

To investigate the impact of sampling time and location on enterococci concentration using the additional winter 2014 samples, a GLM with the negative binomial distribution (Venables et al. 2002) was used as is appropriate for count data with high variance relative to the mean (Crawley et al. 2007). Sum contrasts were used for both site and sampling time. The Akaike information criterion (AIC) determined the selection of the best-fit model. Tukey's allway, pairwise comparisons were conducted between sampling times and among sites using glht.

Because macroalgal $\delta^{15} \mathrm{~N}$ data were non-normal, the Kruskal-Wallis test was used to determine variation in $\delta^{15} \mathrm{~N}$ among sites. The relationships between PGA measures and colony size, $\delta^{15} \mathrm{~N}$, and enterococci counts were investigated with linear regressions. In cases where analysis of Cook's distance detected possible outliers or points with high influence, an additional regression excluding those points was performed.

All analyses are performed at significance level $\alpha=0.05$, except in post hoc tests where Bonferroni-corrected p-values are given.

\section{Results}

\subsection{Spatial patterns of $\mathrm{P}$. lobata growth anomalies and coral cover}

PGA prevalence and PGA severity varied significantly by site (Fig. 3A, B, prevalence: likelihood ratio test $(\mathrm{LRT}): \chi^{2}(9)=39.4, \mathrm{p}<0.05$, severity: LRT: $\left.\chi^{2}(9)=53.0, \mathrm{p}<0.05\right)$. Highest values occurred in Waialea, the Puakō Boat Ramp, and Paniau (prevalence: $37.5 \pm 6.1 \%, 35.8 \pm$ $3.1 \%$, and $27.6 \pm 4.8 \%$, resp.; severity: $1.8 \pm 0.2,2.1 \pm 0.4$, and $0.9 \pm 0.1$ PGAs per colony, resp.). The lowest measures of disease were found at SA40, with a prevalence of $13.8 \pm 1.1 \%$ and a severity of $0.3 \pm 0.05$ PGAs per colony. Mean PGA severity and prevalence for the entire study region were $20.5 \pm 0.7 \%$ and $0.63 \pm 0.03$ PGAs per colony, respectively. Percent coral cover varied significantly by site (Fig. 3C, ANOVA: $F(9,589)=17.2, p<0.05$ ), though not in a recognizable geographic pattern. Mean percent coral cover ranged from $13.4 \pm 1.6 \%$ at the Condos site to $48.3 \pm 3.2 \%$ at SA88, with an overall mean of $44.6 \pm 0.4 \%$.

\subsection{Host demographic patterns of $\mathrm{P}$. lobata growth anomalies}

PGA prevalence was significantly predicted by colony size (Fig. 4, linear model, F $(1,8)=$ $9.50, \mathrm{p}<0.05, \mathrm{R}^{2}=0.49$ ). Notably, omitting an outlier (Waialea) with high influence still yielded a strong, significant relationship $\left(\operatorname{lm}, \mathrm{F}(1,7)=15.88, \mathrm{p}<0.05, \mathrm{R}^{2}=0.65\right)$. Similarly, PGA severity increased with the size of the colony $\left(\operatorname{lm}, \mathrm{F}(1,8)=11.76, \mathrm{p}<0.05, \mathrm{R}^{2}=0.54\right)$. However, this relationship was driven by high disease and large colonies at PBR, suggesting that other, more site-specific factors may play greater roles in determining PGA severity (a linear regression omitting PBR was non-significant: $\mathrm{F}(1,7)=3.41, \mathrm{p}=0.11, \mathrm{R}^{2}=0.23$ ).

\subsection{Enterococci concentrations}

Enterococci concentration varied greatly within and across study sites (Fig. 5). However, due to the high variability within sites (such as differences in local SGD input, tide, circulation, sediments, and wave protection) there were no significant differences in enterococci concentrations among sites. Anchialine pools were also variable, with marginally non-significant differences among sites (Fig. 5, Table 1). The mean enterococci concentrations only exceeded 
the recommendations of $104 \mathrm{CFU} / 100 \mathrm{~mL}$ for some tide pools. Four of the five anchialine pools had concentrations greatly exceeding the limits of $104 \mathrm{CFU} / 100 \mathrm{~mL}$.

Incorporating additional data from sampling in January 2014, a model that includes site, sampling time, and the interaction between site and sampling time best predicts enterococci concentration (Fig. 6, LRT: $\chi^{2}(14)=85.2, \mathrm{p}<0.05$ ), as the AIC value is much lower than those of the other models (Table 2). The results of the multiple comparisons by sampling time show that enterococci concentration was significantly higher following the first rainfall event (postrainfall I) compared to both the summer and the second post-rainfall event (post-rainfall II) sampling times ( $\mathrm{p}<0.05$ for both). Multiple comparisons by sites indicate overall significant differences among sites (Fig.6); however, as predicted by the model, these differences are not consistent between sampling times.

\section{4. $\delta^{15} N$ analyses}

Measures of $\delta^{15} \mathrm{~N}$ in deployed algae did not vary significantly by site $\left(\chi^{2}=9.0637, \mathrm{df}=5\right.$, $\mathrm{p}=0.107$ ), though the initial values (post-starvation, pre-deployment) were on average lower than those of the treatments by $0.4 \pm 0.1 \%$. The Condos site had the greatest $\delta^{15} \mathrm{~N}$. Percent nitrogen differed significantly by site for deployed algae (ANOVA, F(5,54) = 14.47, $\mathrm{p}<0.05$ ), with Waialea Bay and Condos significantly higher than all sites except Paniau. While these data alone do not point to a source of pollution, the differences in $\% \mathrm{~N}$ indicate that there is variation in the nitrogen load at the different sites. Additionally, $\delta^{15} \mathrm{~N}$ analysis on resident Ulva found significant differences between the SA80 and Condos sites $(\mathrm{t}(7.035)=18.1526, \mathrm{p}<0.05)$, with the $\delta^{15} \mathrm{~N}$ of Condos $(8.6 \pm 0.1 \%$ ) being nearly double that of SA80 $(4.6 \pm 0.2 \%$ ) and much higher than the incubated algae.

\subsection{Relationship between PGAs and indicators of sewage pollution}

$\delta^{15} \mathrm{~N}$ and enterococci concentration were significantly related as indicated by linear models (Fig. 7, $\left.1 \mathrm{~m}, \mathrm{~F}(1,3)=10.66, \mathrm{p}=0.047, \mathrm{R}^{2}=0.71\right)$. However, the slope was small (0.02), two data points were highly influential, and there was a small number of data points $(n=5)$.

Open shoreline enterococci concentration and PGA severity were positively related (Fig. $\left.8, \operatorname{lm}, \mathrm{F}(1,8)=8.632, \mathrm{p}=0.019, \mathrm{R}^{2}=0.46\right)$. This strong relationship should be interpreted cautiously because the relationship is driven largely by the Puako Boat Ramp data point with particularly high enterococci concentrations and PGA severity. While not statistically significant, a similar trend was found in open shoreline enterococci concentration and PGA prevalence ( $1 \mathrm{~m}$, Table 1), and also driven by the same Puakō Boat Ramp data point. Omitting the influential Puako Boat Ramp point removed any relationships between enterococci concentration and both PGA severity and prevalence (severity: $F(1,7)=0.1599, p=0.70, R^{2}=-0.12$; prevalence: $F(1,7$ ) $=0.3836, \mathrm{p}=0.56, \mathrm{R}^{2}=-0.08$ ). Additionally, both tide pool and combined (open shoreline + tide pool) enterococci concentrations did not vary significantly with PGA prevalence or severity ( $\mathrm{lm}$, Table 1).

No significant relationship was found between $\delta^{15} \mathrm{~N}$ and PGA prevalence nor severity (lm, Table 1).

\subsection{Coral cover and indicators of sewage pollution}

Coral cover did not vary significantly with enterococci concentration ( $1 \mathrm{~m}$, Table 1$)$. However, a linear model showed a strong negative relationship between $\delta^{15} \mathrm{~N}$ and coral cover (Fig. 9, $\mathrm{F}(1,3)=112.4, \mathrm{p}<0.05, \mathrm{R}^{2}=0.97$ ). 


\section{Discussion}

Sewage pollution is a widespread coastal issue impacting many coral reef environments worldwide. As a multiple stressor, sewage pollution can impact many aspects of coral reef health, including disease (Wear \& Vega Thurber 2015). Despite Puakō's reputation as one of Hawai'i's healthiest coral reefs, here we provide evidence that sewage pollution is entering the marine environment, is linked to reduced coral cover, and may facilitate the coral disease Porites growth anomalies (PGAs).

As snapshot and integrative metrics of sewage pollution, respectively, enterococci concentrations and $\delta^{15} \mathrm{~N}$ measures are rarely used in conjunction to relate possible sewage impacts on coral reefs. Either one or the other is used, and if both are, they are used to validate the other (Baker et al. 2010, Moynihan et al. 2012). We went futher to sample both enterococci concentrations and macroalgal bioassay $\delta^{15} \mathrm{~N}$ in relation to a highly prevalent coral disease. As our results have shown, enterococci concentrations are intermittent (Fig. 6), changing in spatial pattern following rain events and possibly varying by season, which typically have different levels and patterns of precipitation. It was also only in this temporal-spatial analysis that significant differences between sites in enterococci concentration were significant, not in the summer sampling alone. This highlights the importance of long-term sampling of enteroccoci to capture the temporal patterns of sewage pollution entering the marine environment, as snapshot sampling is insufficient to elucidate these patterns.

Although the quantification of enterococci concentrations in seawater are used by US governmental agencies to monitor human health risks and in numerous studies to detect sewage pollution, the method has limitations. Several factors can affect enterococci concentrations in seawater, possibly making them less reliable as indicators of human sewage, including nonhuman animal wastes (birds, invertebrates, fish, etc.), disruption of environmental reservoirs (sands and other sediments), dilution, and exposure (rev. in Staley et al. 2014, Byappanahalli et al. 2012). One alternative explanation for high enterococci concentrations along the shoreline and tidepools in Puakō is visitation by green sea turtles (Chelonia mydas), which are common in the area. The high concentrations of enterococci in anchialine pools (which they cannot access) allow us to infer sewage pollution as the source in Puako.

The $\delta^{15} \mathrm{~N}$ of resident algae collected at the Condos $(8.6 \pm 0.1 \%$ o $)$ and SA40 $(4.6 \pm 0.2 \%$ ) sites were high and indicative of sewage pollution. The $\delta^{15} \mathrm{~N}$ of the Condos algae were consistent with that found in Dailer et al. 2011. That of SA80 may still reflect sewage pollution (based on minimum values of Constanzo et al. 2001), but falls between values of soil (2.3\%) and surface seawater (7\%) based on values found in Derse et al. 2007. Condos and SA 80 resident algae $\delta^{15} \mathrm{~N}$ were significantly different from each other, which suggests shoreline sampling of resident algae or more nearshore, surface bioassays could be used to detect differences in $\delta^{15} \mathrm{~N}$ and thus sources of nitrogen along the coast. These finding are consistent with other studies that have shown the efficacy of assessing macroalgal $\delta^{15} \mathrm{~N}$ to determine sources of nitrogen entering the marine environment (Lapointe et al. 2005, Costanzo et al. 2001, 2005, Baker et al. 2013, Dailer et al. 2010, 2011, Moynihan et al. 2012).

In contrast, $\delta^{15} \mathrm{~N}$ values found in our macroalgal bioassay were not significantly different among sites and low compared to published values, making them closer to those of fertilizer or biologically-fixed nitrogen $(\sim 0 \%$ o) than those more indicative of sewage pollution $(\sim 10 \%$ or greater, Heaton 1986). However, these values are not too low to be influenced by sewage pollution as they could represent 1) lower influence of sewage pollution and greater homogeneity 
of water more offshore, where our surveys and bioassays were located, 2) limitations to nitrogen uptake at reef-level (consistent with findings of Dailer et al. 2010 that surface-deployed algae have higher $\% \mathrm{~N}$ and $\delta^{15} \mathrm{~N}$ values than those at depth), and/or 3) a short deployment time. Values of deployed macroalgae in other studies that may indicate sewage pollution vary from $3 \%$ (Constanzo et al. 2001) to 50.1\%o (Dailer et al. 2010), a large range that reflects variation in the degree of sewage input, location of sampling, and other aspects of the samplings. Dailer et al. (2010) found that surface bioassay algae could reach values comparable to those of collected resident algae in 7 days; however, the location of our assays at depth and the lack of sewage inputs during that time could have required a longer time to do the same.

Sewage pollution may affect multiple aspects of coral health, with one main concern often being its nutrient component (rev. in Fabricius 2005 and Wear and Vega Thurber 2015). The few studies that have studied the relationship between sewage pollution and coral disease find that sewage pollution exacerbates disease (Kaczmasrky et al. 2005, Sutherland et al. 2010). In our study, PGA severity (number of PGAs per colony) was positively related to enterococci concentration (Fig.8). However, the relationship was driven by the high-enterococci concentrations and high-disease levels at the Puakō Boat ramp. Additionally, distance between the shoreline enterococci samplings and more offshore coral disease surveys complicates the relationship. This is not unexpected, as survey sites were chosen to be further offshore in order to have sufficient coral populations for disease measures. Futher inshore, there were fewer colonies and a greater proportion were unhealthy with sedimentation and algal overgrowth (Yoshioka \& Kim pers. obs.). This skews our results conservatively, towards less-impacted colonies. $\delta^{15} \mathrm{~N}$ analyses were less informative, likely due to low sample size and among-site variation. Although no other metrics of sewage pollution were significantly related to coral disease, $\delta^{15} \mathrm{~N}$ was strongly negatively related with \% coral cover, despite low among-site differences (Fig. 9). The small number of points $(n=5)$ requires greater sampling and study to confirm this relationship and its mechanism. Additionally, our bioassays revealed that $\% \mathrm{~N}$ did vary among sites, with highest levels at Waialea Bay and Condos, suggesting that nitrogen inputs into Puakō reefs differ along the coastline, regardless of the source.

Variation in host factors can also influence coral disease (Sutherland et al. 2004, Harvell et al. 2007). In this study PGA prevalence and severity were both positively related with colony size, though severity was driven by large colony sizes and high disease at PBR (Fig. 4 for PGA prevalence). Larger colonies are typically older, which theoretically provides a larger spatial and temporal opportunity for disease to occur. Additionally, larger colonies were generally found in more embayed sites such as Waialea, Puakō Boat Ramp and to a lesser extent, Paniau. The protection from wave action in embayed sites generally allows for more extensive reefs and larger coral colony sizes (Todd et al. 2008). However, if embayments limit water movement and the flushing of contaminants and pathogens, then they may also exacerbate disease (Couch et al. 2014). Other studies have found negative relationships between water movement and coral disease (Couch 2014, Burns et al. 2011) and a highly significant effect of coral size on PGA (Couch 2014, Couch et al. 2014). Although it is uncertain whether colony size or water movement is driving high disease measures, the evidence suggests higher risk of disease in embayments and prioritizes the reduction of possible stressors in these areas. Measures of water movement, such as clod cards, may help to distinguish these environmental and host factors.

PGAs are among the most prevalent coral diseases on Hawai'i Island, with Aeby et al. (2011b) finding an average of $0.52 \pm 0.2 \%$ colonies afflicted for the island and Couch et al. (2014) finding an 26-fold greater $(13.7 \pm 0.82 \%)$ prevalence in West Hawai' $i$. Our site with the 
lowest disease measures, SA40, had a similar prevalence of $13.8 \pm 1.1 \%$. Overall,the prevalence of PGAs in our study was $20.5 \pm 0.7 \%$, with a maximum of $37.6 \pm 6.2 \%$ at Waialea. These measurements dwarf prevalences found by Aeby et al. (2011a) for the entire Indo-Pacific region: an average of $0.21 \%$ with a maximum of $16.7 \%$ (in the Hawaiian Islands). Even with the possibility of minor differences in sampling and identification of PGAs due to their variable nature, the relatively high prevalence of PGAs in Puako highlights the region as one of concern for Hawai'i Island and the Hawaiian Islands in general.

This study adds to the growing body of research implicating sewage pollution as an important factor in declining coral reef health. Sewage pollution, detected through enterococci concentrations and $\delta^{15} \mathrm{~N}$ macroalgal bioassays, may exacerbate coral diseases and reduce coral cover. Sewage inputs are influenced by rainfall, highly variable over space and time, and challenging to pin down. Furthermore, Puakō has been identified as a region of high disease, despite its reputation as a healthy reef. It is important to note that while most samplings fell below the single sample maximum of $104 \mathrm{CFU} / 100 \mathrm{~mL}$ as recommended by the USEPA and Hawai'i State Department of Health (Hawai'i Administrative Rules §11-54-8, 2013), Waialea and Puakō Boat Ramp (post-rainfall I), tidepools at SA40, SA80, and SA152, and four of the five anchialine pools greatly exceeded the limits (Fig. 5), constituting a public health concern. Although the exact relationship between sewage pollution and levels of coral disease remains uncertain in Puakō, our work highlights priorities for future studies of sewage pollution and coral reef health there and elsewhere: 1) improve the temporal resolution of sewage pollution metrics to capture variation due to intermittent pulses of sewage pollution, 2) develop and utilize alternative metrics for sewage pollution, such as microbial source tracking, and 3) quantify water movement, especially in embayments where reefs may be particularly affected by decreased water quality. Sewage pollution is a pervasive threat to both human and coral health; improved studies can help us manage health of our coral reefs worldwide.

\section{Acknowledgements}

Special thanks to K. Bitan, K. Bland, L. Callery, and N. Rivlin for help with sample collection and laboratory assistance. Investigators also thank L. Kramer, C. Couch, M. Shulman, A. Moore and C. Wiggins for additional guidance. The Nature Conservancy, Blue Wilderness Dive Co., and Hawaiian Preparatory Academy provided logistical and facilities support. Generous funding was provided by the Puakō Community Association and the NSF funded Cornell Biology Research Fellowship awarded to R. Yoshioka. Ulva fasciata bioassays were performed under Hawai'i DAR Special Activity Permit 2013-64.

\section{Author Contributions}

CDH, CJSK, and RMY designed the study with help from RM. CJSK and RMY conducted most of the fieldwork with assistance from CDH and AMT. RMY and AMT conducted the statistical analyses. RMY and RM produced the figures. RMY, CJSK, and CDH wrote the manuscript with input from AMT and RM. 


\section{References}

Aeby GS, Williams GJ, Franklin EC, Haapkyla J, Harvell CD, Neale S, Page CA, Raymundo LJ, Vargas-Angel B, Willis BL, Work TM, Davy SK (2011a) Growth anomalies on the coral genera Acropora and Porites are strongly associated with host density and human population size across the Indo-Pacific. PLoS one 6:e16887

Aeby GS, Williams GJ, Franklin EC, Kenyon J, Cox EF, Coles S, Work TM (2011b). Patterns of coral disease across the Hawaiian Archipelago: relating disease to environment. PLoS one 6(5), e20370.

Baker DM, Rodriguez-Martinez RE, Fogel ML. (2013). Tourism's nitrogen footprint on a Mesoamerican coral reef. Coral Reefs 32(3): 691-699.

Baker DM, Jordan-Dahlgreen, Maldonado MA, Harvell CD (2010) Sea fan corals provide a stable isotope baseline for assessing sewage pollution in the Mexican Caribbean. Limnol Oceanogr 55:2139-2149

Bates D, Maechler M, Bolker B, Walker S, Christensen RH, Singmann H, Dai B, Eigen C, Rcpp L. (2015). Package 'lme4'.

Bruno JF, Petes LE, Harvell CD, Hettinger A (2003) Nutrient enrichment can increase the severity of coral diseases. Ecology Letters 6:1056-1061

Burge CA, Eakin CM, Friedman CS, Froelich B, Hershberger PK, Hofmann EE, Petes LE, Prager KC, Weil E, Willis BL, Ford SE, Harvell CD (2014) Climate change influences on marine infectious disease: implications for management and society. Annual Review of Marine Science 6:249-277.

Burns JHR, Takabayashi M (2011) Histopathology of Growth Anomaly Affecting the Coral, Montipora capitata: Implications on Biological Functions and Population Viability. Plos One 6:e28854

Burns JHR, Rozet NK, Takabayashi M (2011) Morphology, severity, and distribution of growth anomalies in the coral, Montipora capitata, at Wai'ōpae, Hawai'i. Coral Reefs 30:819826

Costanzo SD, Udy J, Longstaff B, Jones A (2005). Using nitrogen stable isotope ratios $\left(\delta^{15} \mathrm{~N}\right)$ of macroalgae to determine the effectiveness of sewage upgrades: changes in the extent of sewage plumes over four years in Moreton Bay, Australia.Mar Pollut Bull 51(1): 212217.

Costanzo SD, O’donohue MJ, Dennison WC., Loneragan NR, Thomas M (2001). A new approach for detecting and mapping sewage impacts. Mar Pollut Bull 42(2): 149-156.

Couch CS (2014). Intrinsic host and extrinsic environmental factors of coral health and disease. PhD Dissertation, Cornell University, p 244

Couch CS, Mydlarz LD, Harvell CD, Douglas NL (2008) Variation in measures of immunocompetence of sea fan coral, Gorgonia ventalina, in the Florida Keys. Mar Biol 155:281-292

Couch CS, Garriques JD, Barnett C, Preskitt L, Cotton S, Giddens J, Walsh W (2014) Spatial and Temporal Patterns of Coral Health and Disease along Leeward Hawai'i Island. Coral Reefs. Coral Reefs 33:693-704

Crawley, MJ (2007) The R Book. West Sussex: John Wiley \& Sons, Ltd., Print. ISBN 9780470510247 
Dailer M, Smith C, Glenn C (2011) Preventing the introduction and spread of nutrient driven invasive algal blooms and coral reef degradation in West Hawai'i. NOAA report

Dailer ML, Knox RS, Smith JE, Napier M, Smith CM (2010) Using $\delta^{15} \mathrm{~N}$ values in algal tissue to map locations and potential sources of anthropogenic nutrient inputs on the island of Maui, Hawai'i, USA. Mar Pollut Bull 80:655-671

Derse E, Knee KL, Wankel SD, Kendall C, Berg CJ, Paytan A (2007) Indentifying Souces of Nitrogen to Hanalei Bay, Kauai, Utilizing the Nitrogen Isotope Signature of Macroalgae. Environ Sci Technol 41:5217-5223.

Dudley BD, MacKenzie RA, Sakihara TS, Dulaiova H, Waters CA, Hughes RF, Ostertag R (2014). Influences of N-Fixing and Non-N-Fixing Vegetation and Invasive Fish on Water Chemistry of Hawaiian Anchialine Ponds 1. Pacific Science 68(4): 509-523.

Fabricius KE (2005). Effects of terrestrial runoff on the ecology of corals and coral reefs: review and synthesis. Mar Pollut Bull 50(2): 125-146.

Fertig B, Carruthers TJB., Dennison WC, Jones AB., Pantus F, Longstaff B (2009). Oyster and macroalgae bioindicators detect elevated $\delta 15 \mathrm{~N}$ in Maryland's Coastal Bays. Estuaries and Coasts 32(4): 773-786.

Friedlander A, Aeby G, Brainard R, Brown E, Clark A, Coles S, Dollar S, Hunter C, Jokiel P, Smith J, Walsh B, Williams I, Wiltse W (2008) The state of coral reef ecosystems of the main Hawaiian islands. NOAA Technical Memorandum NOS NCCOS, 73:219-269

García-Sanz T, Ruiz JM, Pérez M, Ruiz M (2011). Assessment of dissolved nutrients dispersal derived from offshore fish-farm using nitrogen stable isotope ratios $(\delta 15 \mathrm{~N})$ in macroalgal bioassays. Estuarine, Coastal and Shelf Science, 91(3): 361-370.

Harvell CD, Jordán-Dahlgren E, Merkel S, Rosenberg E, Raymundo L, Smith GW, Weil E, Willis BL (2007) Coral disease, environmental drivers and the balance between coral and microbial associates. Oceanography 20:58-81

Hawai'i Administrative Rules (2013). Amendment and Compilation of Chapter 11-54. State of Hawai'i Department of Health.

Heaton THE (1986). Isotopic studies of nitrogen pollution in the hydrosphere and atmosphere: a review. Chemical Geology: Isotope Geoscience section 59: 87-102.

Irikawa A, Casareto BE, Suzuki Y, Agostini S, Hidaka M, van Woesik R (2011) Growth anomalies on Acropora cytherea corals. Mar Pollut Bull 62:1702-1707

Johnson, AG (2008) Groundwater discharge from the leeward half of the Big Island, Hawai'i. Master of Science thesis, University of Hawai'i.

Kaczmarsky LT, Draud M, Williams EH (2005). Is there a relationship between proximity to sewage effluent and the prevalence of coral disease. Caribb J Sci 41(1): 124-137.

Knee KL, Street JH, Grossman EE, Boehm AB, Paytan A (2010) Nutrient inputs to the coastal ocean from submarine groundwater discharge in a groundwater-dominated system: Relation to land use (Kona coast, Hawaii, U.S.A.). Limnol Oceanogr 55(3):1105-1122

Lapointe, BE, Barile PJ, Littler MM, Littler DS (2005). Macroalgal blooms on southeast Florida coral reefs: II. Cross-shelf discrimination of nitrogen sources indicates widespread assimilation of sewage nitrogen. Harmful Algae 4(6): 1106-1122.

Lesser MP, Jarett JK (2014) Culture-dependent and culture-independent analyses reveal no prokaryotic community shifts or recovery of Serratia marcescens in Acropora palmata with white pox disease. FEMS Microbiology Ecology 88(3):457-467 
Minton D, Conklin E, Weiant P, Wiggins C (2012) 40 Years of Decline on Puakō's Coral Reefs A review of Historical and Current Data (1970-2010). The Nature Conservancy.

Moynihan MA, Baker DM, Mmochi AJ (2012). Isotopic and microbial indicators of sewage pollution from Stone Town, Zanzibar, Tanzania. Mar Pollut Bull 64(7): 1348-1355.

Risk MJ, Lapointe BE, Sherwood OA, Bedford BJ (2009) The use of $\delta^{15} \mathrm{~N}$ in assessing sewage stress on coral reefs. Mar Pollut Bull 58:793-802

Ruiz-Moreno D, Willis BL, Page AC, Weil E, Croquer A, Vargas-Angel B, Jordan-Garza AG, Jordan-Dahlgren E, Raymundo L, Harvell CD (2012) Global coral disease prevalence associated with sea temperature anomalies and local factors. Dis Aquat Org 100:249-261

Spies NP, Takabayashi M (2013) Expression of galaxin and oncogene homologs in growth anomaly in the coral Montipora capitata. Dis Aquat Org 104:249-256

Staley C, Dunny GM, Sadowsky MJ (2014). Environmental and Animal-Associated Enterococci. Advances in Applied Microbiology 87:147-186

Street JH, Knee KL, Grossman EE, Paytan A (2008) Submarine groundwater discharge and nutrient addition to the coastal zone and coral reefs of leeward Hawai'i. Marine Chemistry 109:355-376

Sutherland KP, Porter JW, Turner JW, Thomas BJ, Looney EE, Luna TP, Meyers MK, Futch JC, Lipp EK (2010) Human sewage identified as likely source of white pox disease of the threatened Caribbean elkhorn coral, Acropora palmata. Environmental Microbiology 12:1122-1131

Sutherland KP, Porter JW, Torres C (2004). Disease and immunity in Caribbean and IndoPacific zooxanthellate corals. Marine ecology progress series 266: 265-272.

Szmant AM (2002). Nutrient enrichment on coral reefs: is it a major cause of coral reef decline?. Estuaries 25(4): 743-766.

Todd PA (2008). Morphological plasticity in scleractinian corals. Biological Reviews 83(3): 315-337.

Torsten Hothorn, Frank Bretz and Peter Westfall (2008). Simultaneous Inference in General Parametric Models. Biometrical Journal 50(3):346-363.

US Environmental Protection Agency (2009). Method 1600: Enterococci in Water by Membrane Filtration Using membrane-Enterococcus Indoxyl-B-D-Glucoside Agar (mEI). United States Environmental Protection Agency Protocol.

US Census Bureau (2010). Puako CDP, Hawaii. American FactFinder. Accessed 29 December 2015 at http://factfinder.census.gov/faces/nav/jsf/pages/community_facts.xhtml?src=bkmk

Vega Thurber RL, Burkepile DE, Fuchs C, Shantz AA, McMinds R, Zaneveld JR (2014) Chronic nutrient enrichment increases prevalence and severity of coral disease and bleaching. Global Change Biology 20:544-554.

Vega Thurber RL, Correa AMS (2011) Viruses of reef-building scleractinian corals. Journal of Experimental Marine Biology and Ecology 408:102-113.

Venables WN, Ripley B D (2002) Modern Applied Statistics with S. Fourth Edition. Springer, New York. ISBN 0387954570

Voss JD, Richardson LL (2006) Nutrient enrichment enhances black band disease progression in corals. Coral Reefs 25(4):569-576

Walsh WJ (2013) South Kohala Reefs in Dire Straits. State of Hawai'i Department of Land and Natural Resources, Division of Aquatic Resources 
Wear SL, Vega Thurber R (2015). Sewage pollution: mitigation is key for coral reef stewardship. Annals of the New York Academy of Sciences: 1-16. doi: 10.1111/nyas.12785

Yasuda N, Nakano Y, Yamashiro H, Hidaka M (2012). Skeletal structure and progression of growth anomalies in Porites australiensis in Okinawa, Japan. Dis Aquat Org 97(3):237247 


\section{Artwork and Tables}

\section{Figure Sizing:}

Figure 1: Single Column

Figure 2: Single Colum

Figure 3: Single Column

Figure 4: Single Column

Figure 5: Double Column

Figure 6: Single Column

Figure 7: Single Column

Figure 8: Single Column

Figure 9: Single Column

Figure and Table Captions and Tables (in order of citation in MS):

Figure 1: Porites growth anomalies (PGAs) on Porites lobata. Arrows indicate several conspicuous PGAs. Note lighter pigmentation, raised surface, and enlarged polyps of PGA as shown in inset.

Figure 2: Puakō region and study sites. Ten sites were selected for this study, spanning from Paniau Bay to Waialea Bay. Algal $\delta^{15} \mathrm{~N}$ bioassays were conducted at Waialea, Condos, SA80, SA136, and Paniau. Inset depicts the entire Hawai'i Island with a box indicating the study region.

Figure 3: Mean $( \pm \mathrm{SE})(\mathrm{A})$ PGA prevalence (binomial-family generalized linear mixed model (GLMM), likelihood ratio test (LRT): $\left.\chi^{2}(9)=136.38, \mathrm{p}<0.05\right)$, (B) PGA severity (poissonfamily GLMM, LRT: $\chi^{2}(9)=1076.1, \mathrm{p}<0.05$ ), and $(\mathrm{C})$ percent coral cover by site (ANOVA: $\mathrm{F}(9,589)=17.2, \mathrm{p}<0.05)$. Shared letters indicate no significant difference. The Puakō Boat Ramp is abbreviated as PBR.

Figure 4: PGA prevalence versus colony size (linear model, $F(1,8)=9.50, \mathrm{p}<0.05, \mathrm{R}^{2}=0.49$ ). Omitting an outlier (dark point, Waialea) with high influence still yielded a significant relationship $\left(\operatorname{lm}, \mathrm{F}(1,7)=15.88, \mathrm{p}<0.05, \mathrm{R}^{2}=0.65\right)$.

Figure 5: Enterococci concentration in CFU/100 mL A) overall (combined open shoreline and tide pools), B) open shoreline only, C) tide pools only, and D) anchialine pools. No significant differences were found between sites. Horizontal lines represents Hawai'i State Department of Health single sample maximum of $104 \mathrm{CFU} / 100 \mathrm{~mL}$. The Puako Boat Ramp is abbreviated as PBR.

Figure 6: Mean $( \pm \mathrm{SE})$ open shoreline enterococci concentrations by site on 25 June 2013 (summer) and on 7 January and 13 January 2014 respectively following two rainfall events (postrainfall I and II). Shared letters indicate no significant differences among sites overall as determined by multiple comparisons general linear hypothesis testing, but do not indicate any relationships at or between specific sampling times (negative binomial-family general linear model, likelihood ratio test: $\left.\chi^{2}(14)=85.2, \mathrm{p}<0.05\right)$. Horizontal line indicates single sample maximum of $104 \mathrm{CFU} / 100 \mathrm{~mL}$ as per Hawai'i State regulations. The Puakō Boat Ramp is abbreviated as PBR. 
Table 1: Statistics summary for differences among sites and relationships between predictors of sewage pollution and PGAs. Analysis of Variance is abbreviated as ANOVA and linear model/regression as LM.

\begin{tabular}{l|lllll}
\hline Relationship & Test & $d f$ & $F$ & $p$ & $R^{2}$ \\
\hline $\begin{array}{l}\text { overall (combined shoreline and tidepool) } \\
\text { enterococci concentration vs Site }\end{array}$ & ANOVA & 9,40 & 0.649 & 0.749 & NA \\
$\begin{array}{l}\text { anchialine pool enterococci concentration } \\
\text { vs Site }\end{array}$ & ANOVA & 4,5 & 5.119 & 0.051 & NA \\
$\begin{array}{l}\text { severity vs overall enterococci } \\
\text { concentration }\end{array}$ & LM & 1,8 & 0.0796 & 0.785 & -0.1139 \\
$\begin{array}{l}\text { PGA prevalence vs overall enterococci } \\
\text { concentration }\end{array}$ & LM & 1,8 & 0.6157 & 0.455 & -0.0446 \\
$\begin{array}{l}\text { PGA prevalence vs open shoreline } \\
\text { enterococci concentration }\end{array}$ & LM & 1,8 & 4.063 & 0.0786 & 0.2539 \\
$\begin{array}{l}\% \text { coral cover vs overall enterococci } \\
\text { concentration }\end{array}$ & LM & 1,8 & 0.1393 & 0.719 & -0.1058 \\
$\begin{array}{l}\% \text { coral cover vs open shoreline } \\
\text { enterococci concentration }\end{array}$ & LM & 1,8 & 2.752 & 0.136 & 0.1629 \\
$\begin{array}{l}\text { PGA severity vs algal } \delta^{15} \mathrm{~N} \\
\text { PGA prevalence vs algal } \delta^{15} \mathrm{~N}\end{array}$ & LM & 1,3 & 0.254 & 0.649 & -0.2292 \\
\hline
\end{tabular}

Table 2: Generalized linear model selection using Akaike information criterion (AIC) values. Lower AIC values are interpreted to represent better models. The difference between the best model AIC and the respective model AIC is shown as dAIC.

\begin{tabular}{l|lll}
\hline Model & AIC & $d A I C$ & $d f$ \\
\hline Enterococci concentration vs site x time & 529.7395 & 0 & 16 \\
Enterococci concentration vs site + time & 563.4427 & 33.7032 & 8 \\
Enterococci concentration vs time & 569.5475 & 39.808 & 4 \\
Enterococci concentration vs site & 570.8209 & 41.0814 & 6 \\
Enterococci concentration vs 1 (null) & 585.9854 & 56.2459 & 2 \\
\hline
\end{tabular}

Figure 7: Bioassay algal $\delta^{15} \mathrm{~N}$ versus open shoreline enterococci concentration (linear model, $\left.\mathrm{F}(1,3)=10.66, \mathrm{p}=0.047, \mathrm{R}^{2}=0.71\right)$. Darker points are those with high influence (Condos and SA136); a regression omitting those points is not shown as the resulting model would be uninformative.

Figure 8: Mean site PGA severity versus open shoreline enterococci concentration. Darker point is Puakō Boat Ramp, which is an outlier with high influence due to its particularly high level of disease and enterococci concentration. The linear model for all sites is shown with the solid regression line $\left(\mathrm{F}(1,8)=8.632, \mathrm{p}=0.019, \mathrm{R}^{2}=0.46\right)$; a regression omiting the Puako Boat Ramp point is shown as the shorter dashed line $\left(F(1,7)=0.1599, p=0.7012, R^{2}=-0.1173\right)$.

Figure 9: Percent coral cover versus bioassay algal $\delta^{15} \mathrm{~N}$ (linear model, $\mathrm{F}(1,3)=112.4, \mathrm{p}=$ $\left.0.00179, \mathrm{R}^{2}=0.9653\right)$. Dark points are those with high influence (Condos and Paniau); $\mathrm{a}$ regression omitting these points is not shown as it would be uninformative. 


\section{Figure 2}

\section{Waialea}

\section{Puakō Boat Ramp}

Condos

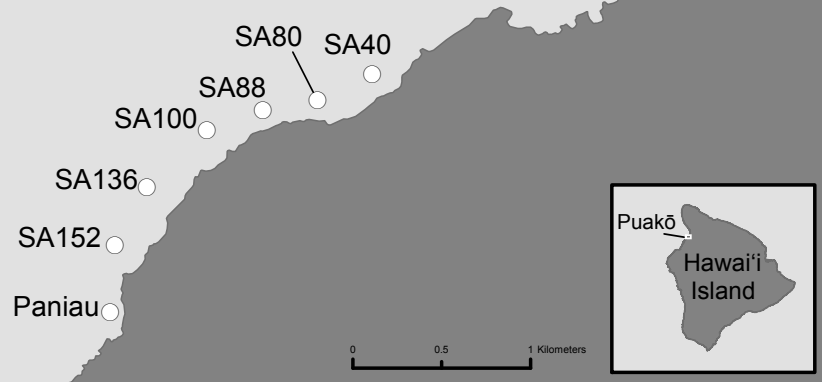



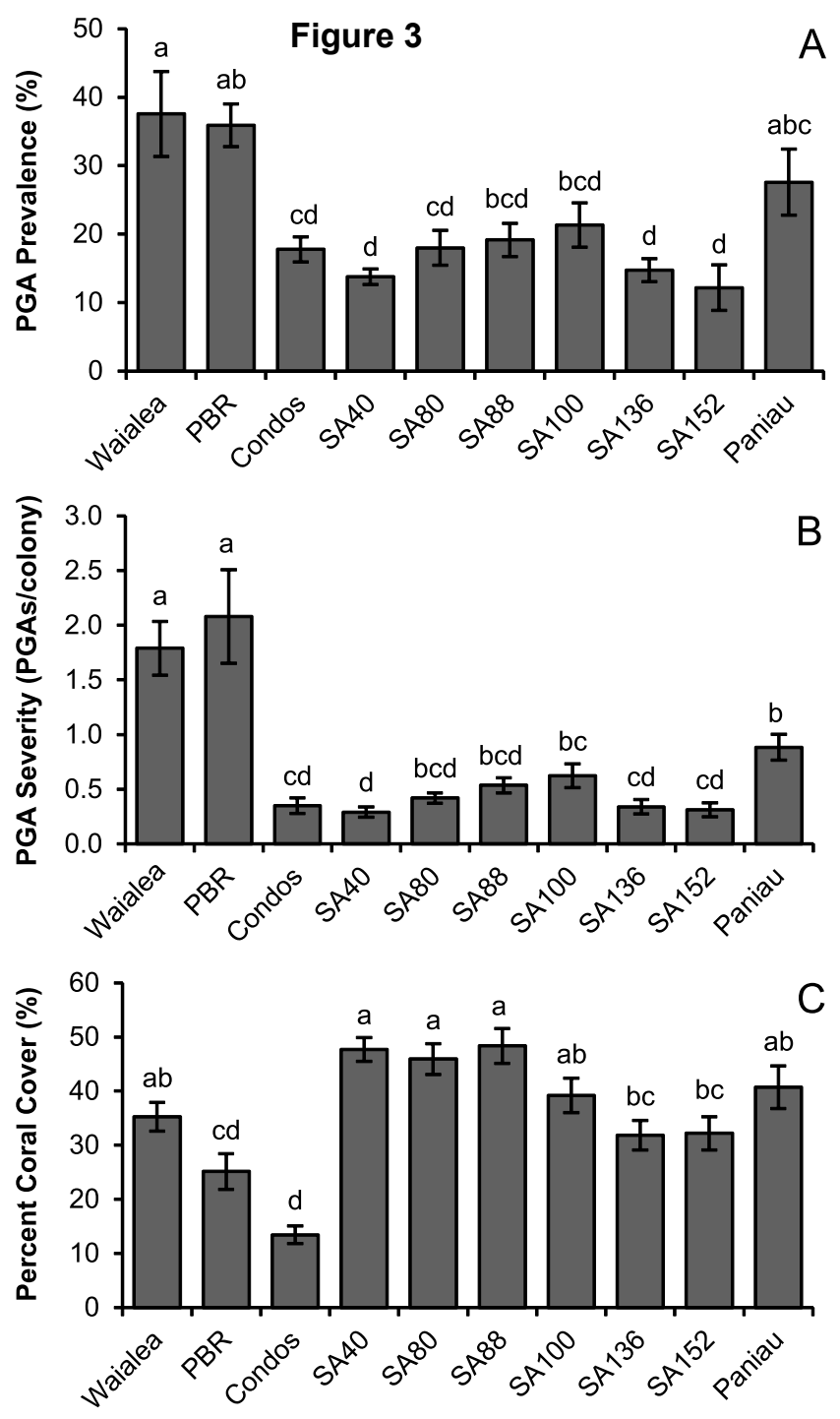


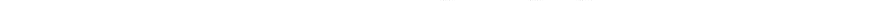




\section{Figure $\mathbf{5}$}

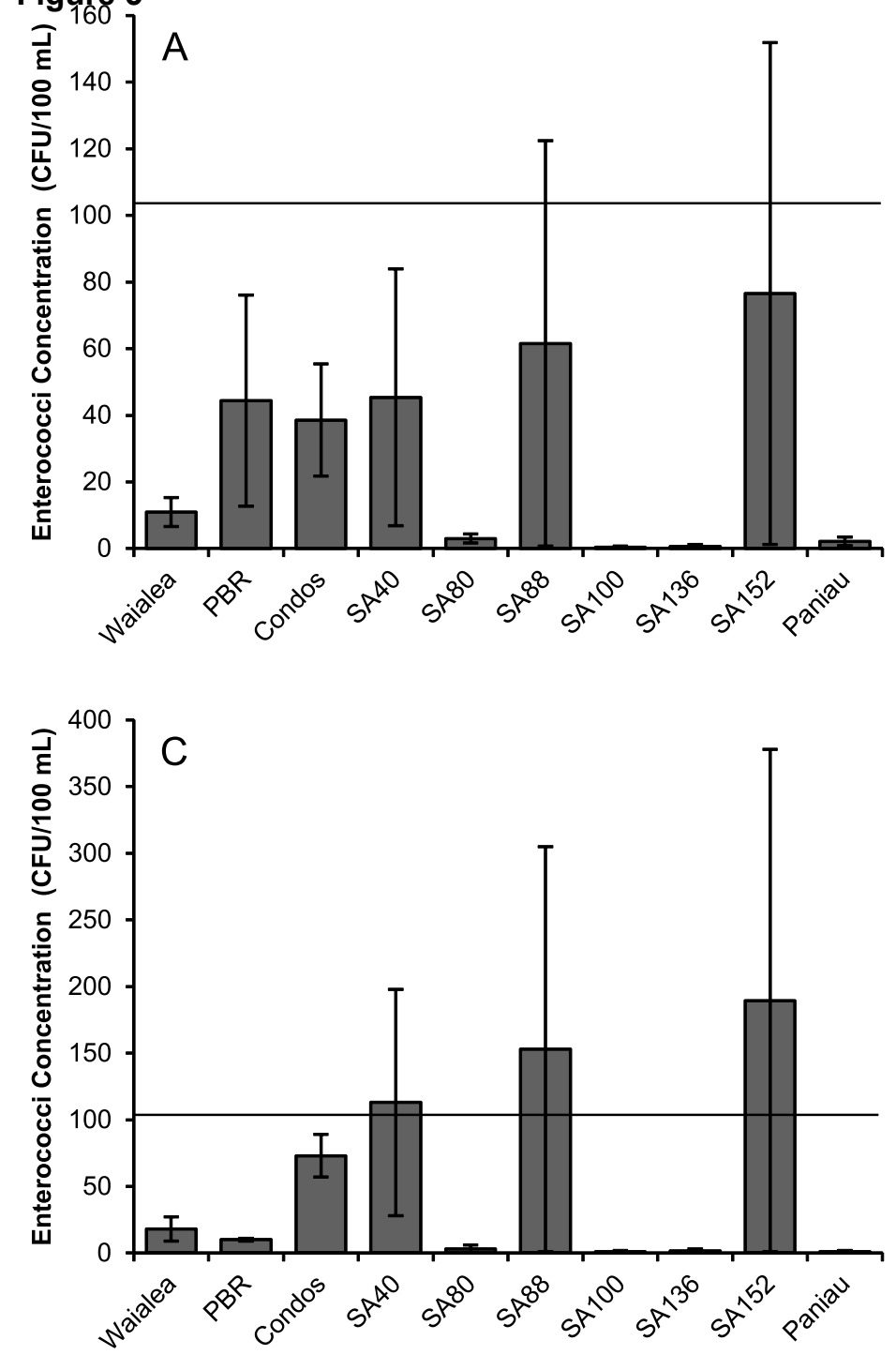

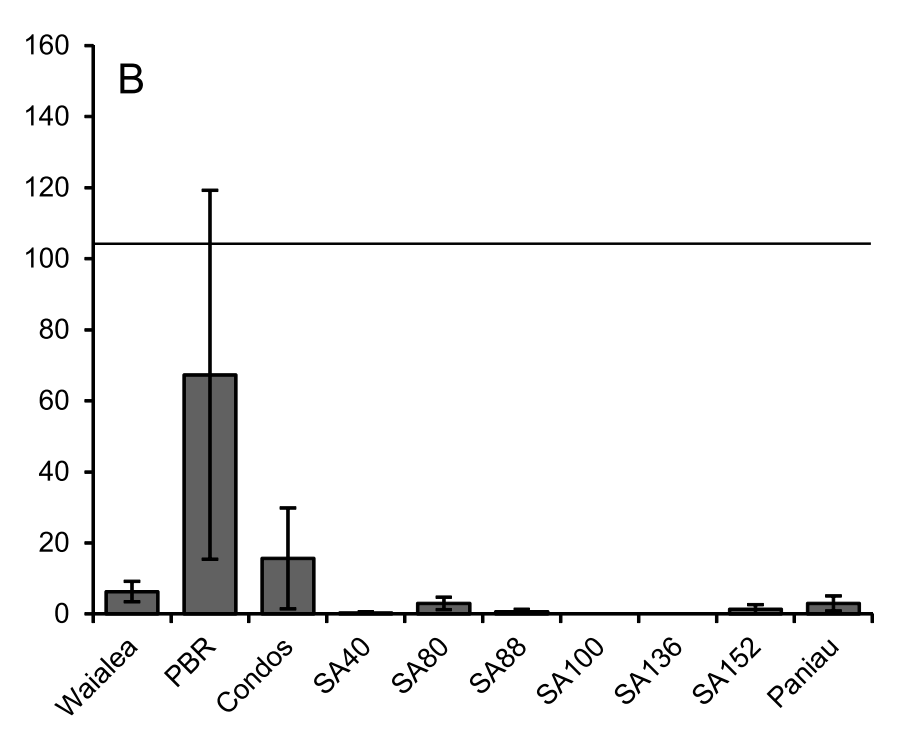

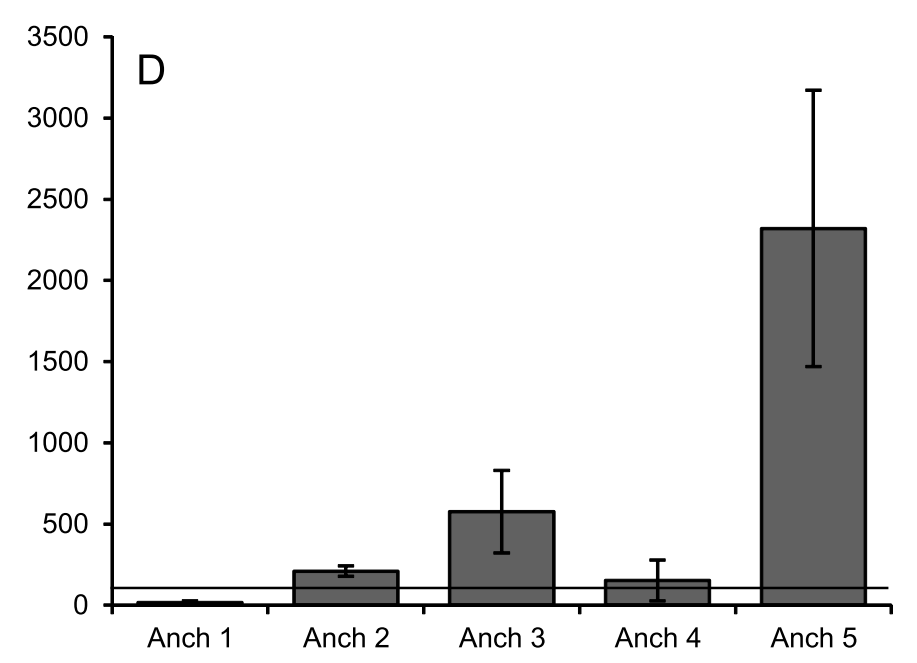




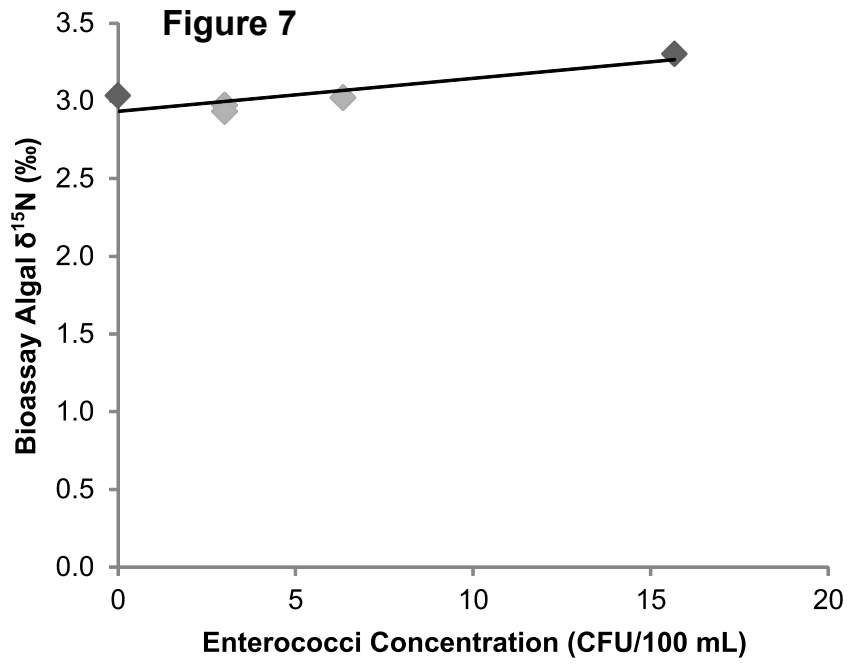




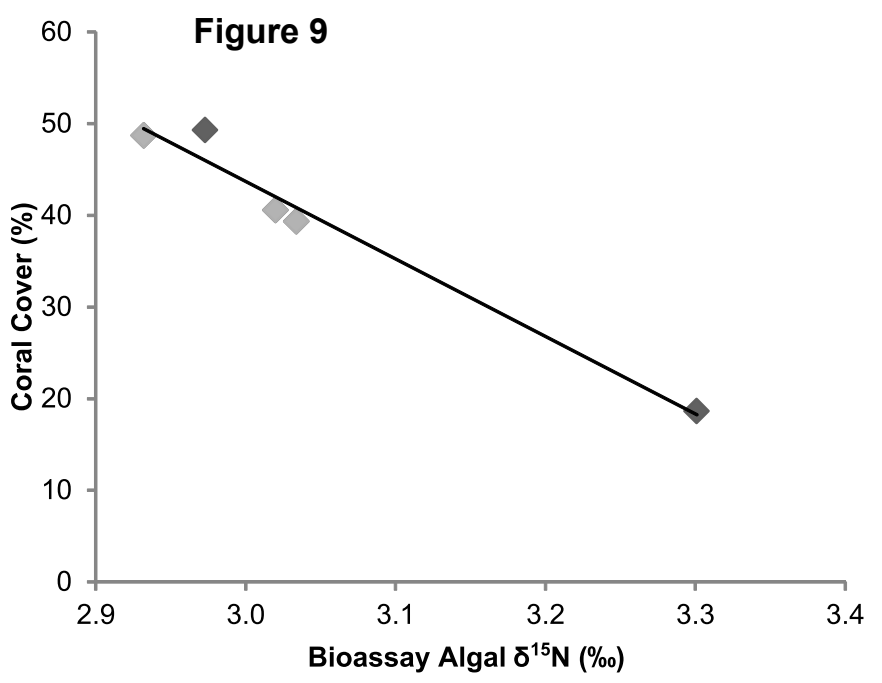

